\title{
Effects of azithromycin on ozone-induced airway neutrophilia and cytokine release
}

\author{
G.I. Criqui*, C. Solomon*, B.S. Welch*, R.E. Ferrando*, H.A. Boushey**, J.R. Balmes**
}

\begin{abstract}
Effects of azithromycin on ozone-induced airway neutrophilia and cytokine release. G.I. Criqui, C. Solomon, B.S. Welch, R.E. Ferrando, H.A. Boushey, J.R. Balmes. (CERS Journals Ltd 2000

ABSTRACT: Exposure of humans to ozone causes increased neutrophils and inflammatory cytokines in airway lining fluid. Recent research shows that macrolide antibiotics may reduce interleukin (IL)-8 production by bronchial epithelial cells and inhibit neutrophil chemotaxis.

A double-blind, cross-over study was performed in which 12 healthy subjects underwent two separate 4-h exposures to 0.2 parts per million ozone while exercising intermittently. In the $73.5 \mathrm{~h}$ before exposure, subjects were pretreated with either $1,250 \mathrm{mg}$ azithromycin or placebo. Sputum induction conducted $74 \mathrm{~h}$ pre- and $18 \mathrm{~h}$ post-exposure was used to measure total cells, per cent neutrophils, IL-6, and IL-8.

There were significant $(\mathbf{p}<0.05)$ pre- to post-exposure increases in total cells, neutrophils, IL-6 and IL-8 in both the azithromycin and placebo arms. However, no significant differences were found between azithromycin and placebo conditions in the post- minus pre-exposure value for these variables.

The results suggest that in healthy subjects, in the design used, azithromycin, in usual clinical doses, does not have anti-inflammatory effects on human airways as indicated in the measured variables.
\end{abstract}

Eur Respir J 2000; 15: 856-862.
*Lung Biology Center and **Cardiovascular Research Institute, Dept of Medicine, University of California, San Francisco, USA.

Correspondence: C. Solomon, Lung Biology Center UCSF, Box 0854, University of California San Francisco, CA 941430854, USA. Fax: 14152064123

\author{
Keywords: Interleukin-8 \\ macrolide antibiotics \\ neutrophils \\ ozone
}

Received: April 221999

Accepted after revision January 122000

Support was provided by the National Institutes of Health (NIH/SCOR/P50 HL56385) and a UCSF Student Research Committee Summer Fellowship.
Exposure of human subjects to ozone $\left(\mathrm{O}_{3}\right)$ has been shown to cause airway inflammation, characterized by submucosal infiltration of neutrophils with concomitant increased levels of neutrophils, proteins, and inflammatory mediators in bronchoalveolar lavage (BAL) fluid, as well as leading to reversible decrements in lung function [1-5]. Recent studies utilizing induced sputum have also demonstrated increased levels of neutrophils and inflammatory mediators following $\mathrm{O}_{3}$ exposure [6-7]. In addition, several recent studies have concluded that macrolide antibiotics may, via inhibitory action on interleukin (IL)8 , have anti-inflammatory properties in addition to their known antibiotic effects [8-12, 13]. Erythromycin has been shown to reduce Haemophilus influenza endotoxininduced neutrophil chemotaxis and release of IL- 6 and IL-8 in cultured human bronchial epithelial cells [8]. Erythromycin, along with roxithromycin and clarithromycin, has also been shown to reduce IL- 8 production by the $1 \alpha, 25$-dihydroxyvitamin D3-stimulated human monocytic cell line, THP-1, after stimulation with lipopolysaccharide and 1\% normal human serum [9]. Erythromycin and clarithromycin reduced IL-8 production by airway epithelial cells taken from patients with chronic airway inflammatory disease and by both unstimulated and IL$1 \alpha$-stimulated human bronchial epithelial cells from the BEAS-2B cell line [10]. Another study [11] showed that pretreatment with roxithromycin or erythromycin lessened the increase in goblet cell secretion and neutrophil accumulation in guinea pig tracheas following inhaled IL-8.
There are also studies in human subjects that demonstrate possible anti-inflammatory effects of macrolides [12, 14]. One experiment showed significant reductions in IL8 and neutrophil chemotaxis in BAL fluid after treatment with erythromycin in patients with cryptogenic organizing pneumonia with BAL fluid neutrophilia, although the experiment lacked a control group [12]. Another study demonstrated that clarithromycin treatment improved lung function and reduced BAL eosinophils and neutrophils in subjects with chronic asthma [14]. While this reduction in eosinophils and neutrophils could be, as the authors suggest, due to the treatment of mycoplasma and chlamydia infections, it is also possible that the changes were caused by anti-inflammatory properties of clarithromycin itself. Because both human studies used patients with respiratory disease, it is uncertain in these experiments whether the observed anti-inflammatory effects of the macrolides are primary, acting via direct suppression of IL-8, or secondary to the antibiotic activity of the macrolides. Macrolides could require an in vivo stimulated or pre-inflammation condition to induce anti-inflammatory effects, as in healthy unstimulated subjects, azithromycin did not change tumour necrosis factor (TNF)- $\alpha$, IL-1 $\beta$, or IL-6 levels in alveolar macrophages or blood [15].

Using $\mathrm{O}_{3}$-induced airway inflammation in healthy human subjects is a good way to evaluate the proposed anti-inflammatory properties of macrolides in humans since there is presumably no infectious agent present 
against which their antibiotic properties might act. The current authors chose to study azithromycin in preference to other macrolides because it has a low incidence of side effects, achieves high concentrations in the alveolar cells of the lung $[13,15,16]$, and its once-daily dosing schedule allows for better monitoring of compliance. While the proposed anti-inflammatory effects of azithromycin have not been studied as extensively as those of several of its macrolide congeners, at least one study has shown in vitro that therapeutic concentrations of azithromycin led to significant reductions in active oxygen generation and neutrophil chemotaxis [17]. $\mathrm{O}_{3}$-induced airway inflammation is typically quantified by measuring cellular and biochemical components of BAL or induced sputum. This experiment was designed to test the hypothesis that pretreatment with azithromycin would lessen the $\mathrm{O}_{3}$-induced increases in IL-8 concentration and per cent neutrophils in induced sputum.

\section{Methods}

\section{Subjects}

The 12 subjects who participated in this study were healthy, nonsmoking volunteers. Health status was screened via a medical history questionnaire in which each subject denied current or suspected pregnancy, allergy to macrolide antibiotics, significant cardiac or pulmonary disease, and current use of medications other than hormonal contraception. Subjects were provided with information about potential risks and gave informed consent prior to participation in the experiment. The experimental protocol and consent form were approved by the University of California, San Francisco Committee on Human Research (CA, USA) and all subjects gave informed written consent and received financial compensation for their participation. After informed consent was obtained, subjects underwent baseline characterization consisting of height, weight, and spirometric lung function measurements (table 1). Pregnancy tests showed that no subjects were pregnant during the experiment. All subjects denied respiratory infection in the month preceding each study arm, abstained from caffeine for $4 \mathrm{~h}$ prior to all testing sessions, and consumed only water for $2 \mathrm{~h}$ prior to, and for $1 \mathrm{~h}$ after, taking each azithromycin or placebo pill. Acetaminophen and hormonal contraception were the only medications other than azithromycin taken by subjects during the study arms except for two subjects each given $180 \mu \mathrm{g}$ of inhaled albuterol to reverse decrements in forced expiratory volume in one second (FEV1) following exposure to $\mathrm{O}_{3}$ and methacholine, respectively. In both cases, at least 12 hours separated administration of albuterol from subsequent testing sessions.

\section{Equipment and measurements}

Spirometric pulmonary function and nonspecific airway responsiveness. Spirometry for the determination of forced vital capacity (FVC) and FEV1 was performed using a dryrolling-seal spirometer (Model No. S400; Spirotech Division, Anderson Instruments, Atlanta, GA, USA) using standardized procedures [18]. Airway responsiveness was determined by the FEV1 response to inhalation of nebulized (Model No. 646; DeVilbiss, Somerset, PA, USA) phosphate-buffered saline (PBS) followed by increasing doses $(0.26,1.53,4.09,10.48 \mu \mathrm{mol})$ of methacholine in PBS delivered via a dosimeter (Rosenthal, Louisville, CO, USA) at the rate of $0.01 \mathrm{~mL} \cdot$ breath $^{-1}$ following a protocol modified from the Lung Health Study [19]. The methacholine dose-response, a measure of airway responsiveness defined as the per cent drop in FEV1 divided by the cumulative dose of methacholine [20], was used to analyse differences in airway responsiveness both within and between the two conditions.

Exposure chamber and atmospheric monitoring. The exposure sessions were performed in a custom-built steel and glass exposure chamber (Model No. W00327-3R; NorLake Inc., Hudson, WI, USA), which is $2.5 \mathrm{~m} \times 2.5 \mathrm{~m} \times 2.4$ $\mathrm{m}$ in size, and has an average airflow rate of $170 \mathrm{~m}^{3} \cdot \mathrm{min}^{-1}$ $\left.550 \mathrm{ft}^{3} \cdot \mathrm{min}^{-1}\right)$. The chamber air supply was sourced from ambient air which was filtered by passing through purifying (Model No. 6239; Purafil, Atlanta, GA, USA) and high efficiency particle (HEPA; Eco-Air, San Diego, CA, USA) filters. The filtered air was dehumidified by passing through a drier (Model No. HC- 575; Cargocaire Engineering Corp., Amesbury, MA, USA). Subsequently, the air temperature was decreased with a chilled-water coil, and the

Table 1. - Subject characteristics

\begin{tabular}{|c|c|c|c|c|c|c|c|c|}
\hline $\begin{array}{l}\text { Subject } \\
\text { No. }\end{array}$ & Sex & $\begin{array}{l}\text { Age } \\
\text { yrs }\end{array}$ & $\begin{array}{l}\text { Height } \\
\mathrm{cm}\end{array}$ & $\begin{array}{c}\text { FEV1 } \\
\text { L }\end{array}$ & $\begin{array}{l}\text { FEV1 } \\
\% \text { pred }\end{array}$ & $\begin{array}{l}\mathrm{FVC} \\
\mathrm{L}\end{array}$ & $\begin{array}{l}\text { FVC } \\
\% \text { pred }\end{array}$ & $\begin{array}{l}\text { Methacholine dose-response } \\
\% \text { drop in FEV1/total dose }\end{array}$ \\
\hline 1 & M & 25 & 180 & 5.21 & 116 & 6.04 & 109 & 0.35 \\
\hline 2 & M & 35 & 180 & 4.83 & 114 & 6.41 & 122 & 0.04 \\
\hline 3 & M & 47 & 178 & 4.33 & 115 & 5.11 & 108 & 0.28 \\
\hline 4 & M & 32 & 178 & 4.13 & 99 & 5.11 & 99 & 2.61 \\
\hline 5 & M & 35 & 171 & 4.27 & 113 & 4.97 & 106 & 0.66 \\
\hline 6 & $\mathrm{~F}$ & 35 & 163 & 2.53 & 88 & 2.63 & 76 & 1.00 \\
\hline 7 & M & 23 & 188 & 5.28 & 108 & 6.02 & 106 & 0.37 \\
\hline 8 & M & 26 & 189 & 5.11 & 103 & 6.57 & 108 & 1.83 \\
\hline 9 & $\mathrm{~F}$ & 25 & 166 & 3.43 & 108 & 4.52 & 118 & 1.84 \\
\hline 10 & $\mathrm{~F}$ & 26 & 171 & 3.42 & 104 & 4.16 & 104 & 6.11 \\
\hline 11 & $\mathrm{~F}$ & 23 & 169 & 3.85 & 117 & 4.53 & 114 & 0.96 \\
\hline 12 & M & 23 & 177 & 3.17 & 86 & 3.69 & 85 & -0.03 \\
\hline Mean \pm SD & & $29.6 \pm 7.4$ & $175.8 \pm 8.1$ & $4.13 \pm 0.88$ & $105.9 \pm 10.5$ & $4.98 \pm 1.17$ & $104.6 \pm 13.0$ & $1.34 \pm 1.71$ \\
\hline
\end{tabular}

FEV1: forced expiratory volume in one second; FVC: forced vital capacity; M: male; F: female. 
Table 2. - Exposure atmospheric charcteristics

\begin{tabular}{lcc}
\hline & \multicolumn{2}{c}{ Exposure condition } \\
\cline { 2 - 3 } & Azithromycin & Placebo \\
\hline Ozone ppm & $0.198 \pm 0.003$ & $0.198 \pm 0.003$ \\
Temperature ${ }^{\circ} \mathrm{C}$ & $20.0 \pm 0.09$ & $20.0 \pm 0.07$ \\
Relative humidity \% & $62.8 \pm 3.8$ & $61.0 \pm 3.0$ \\
\hline
\end{tabular}

Values are mean \pm SD.

humidity increased with steam (Model No. NHMC-050, Nortec, Ogdensburg, NY, USA), to obtain the preset temperature and relative humidity conditions in the chamber. The temperature and relative humidity inside the chamber were monitored (3-min intervals) and controlled throughout the exposures (table 2; Model No. DSC 8500; Johnson Controls, Poteau, OK, USA). $\mathrm{O}_{3}$ was produced with a corona-discharge $\mathrm{O}_{3}$ generator (Model T 408; Polymetrics, San Jose, CA, USA) and analysed with an ultravioletlight photometer (Model 1008 PC; Dasibi, Glendale, CA, USA). The $\mathrm{O}_{3}$ concentration was measured every $30 \mathrm{~s}$ (table 2), displayed in real time (LabVIEW 2; National Instruments, Austin, TX, USA), and stored by a microcomputer (Model IIsi; Apple Computer, Cupertino, CA, USA). The $\mathrm{O}_{3}$ analyser was calibrated biannually by the California Air Resources Board with a standard $\mathrm{O}_{3}$ generator/analyser instrument (Model 1009 IC; Dasibi) and precision-checked in the authors' laboratory every 6 weeks. There were no significant differences between conditions in temperature, relative humidity, or $\mathrm{O}_{3}$ concentration.

Exercise and pulmonary ventilation. During each exposure, exercise was utilized to induce mouth breathing and to increase minute ventilation $\left(V^{\prime} \mathrm{E}\right)$. The exercise consisted of either walking/running on a treadmill (Model No. M9.1, Precor, Bothel, WA, USA) or pedalling a cycle-ergometer (Model No. 90818e, Monark, Varberg, Sweden). The exercise intensity was adjusted for each subject to a target expired $V^{\prime} \mathrm{E}$ of $25 \mathrm{~L} \cdot \mathrm{min}^{-1} \cdot \mathrm{m}^{-2}$ body surface area. During exercise, $V^{\prime} \mathrm{E}$ was calculated from tidal volume and breathing frequency measured using a pneumotachograph (Model No. 3; Fleisch, Rudolph Inst., Kansas City, MO, USA) at the 10- and 20-min interval of each 30-min exercise period. There was no significant difference in the mean $V^{\prime} \mathrm{E}$ between the azithromycin and placebo conditions (mean \pm SD; $46.8 \pm 5.1 \mathrm{~L} \cdot \mathrm{min}^{-1}$ ambient temperature and pressure, saturated (ATPS) versus $47.8 \pm 3.6 \mathrm{~L} \cdot \mathrm{min}^{-1}$ ATPS; $\mathrm{p}=0.47$ ).

Sputum induction. Spirometry was performed immediately pre- and post-sputum induction. To control for airborne infection, all sputum inductions were performed in an isolation booth (Biosafety, San Diego, CA, USA). Subjects inhaled nebulized sterile (DeVilbiss Ultra-Neb 99 this nebulizer generates particles of a mass median aerodynamic diameter of $3.5 \mathrm{~mm}$ and has an output of $5.9 \mathrm{~mL} \cdot \mathrm{min}^{-1}$ ) $3 \%$ saline for $20 \mathrm{~min}$. At each 2 -min interval, throughout the $20 \mathrm{~min}$, subjects were asked to clear saliva from their mouths into a sterile plastic container and then cough into a second such container. The volume of the induced sputum sample was determined and an equal amount of $0.1 \%$ dithiothreitol (Sputalysin 10\%; Behring Diagnostics Inc., Somerville, NJ, USA) was added. The sample was then mixed gently by a vortex and placed in a shaking water bath at $37^{\circ} \mathrm{C}$ for a minimum of $15 \mathrm{~min}$ to ensure complete homogenization. The sample was removed from the water bath periodically for further brief gentle vortexing. After the sample was completely homogenized, the sample was removed from the water bath and a $1 \mathrm{~mL}$ aliquot was placed on ice for total and differential cell counts. To remove cells and debris, the remainder of the sample was centrifuged at $200 \times g$ for $15 \mathrm{~min}$, and the supernatant removed and recentrifuged at $1,800 \times g$ for $15 \mathrm{~min}$. The supernatant was then frozen and stored at $-80^{\circ} \mathrm{C}$.

Cell enumeration. Total cell counts were performed using a haemocytometer (Hausser Scientific, Horsham, PA, USA), and differential cell counts were performed from cytospins subsequently stained (Diff-Quik; Baxter, San Juan, Puerto Rico). Differential (400 nonsquamous cells) and total cell counts were performed in duplicate by two counters.

Biochemical assays. All biochemical variables were measured in the previously frozen supernatant aliquots. Total protein was measured using a commercially available assay (Pierce BCA, Rockford, IL, USA) and myeloperoxidase (MPO), IL-6, and IL-8 were measured using commercial enzyme-linked immunosorbent (ELISA) kits (R\&D systems, Quantikine, Minneapolis, MN, USA, for IL-6 and IL-8; R\&D systems, Oxis International, Portland, OR, USA, for MPO). Concentrations for each variable were determined from light absorbance measured on a microplate reader (Model 450; BIO-Rad, Richmond, CA, USA).

\section{Procedure}

The study used a double-blind, cross-over design in which each of 12 subjects completed two 5-day study arms differing only in azithromycin versus placebo treatment. Of the 12 subjects, seven received azithromycin treatment first and five received placebo treatment first. A minimum of 4 weeks separated day one of the first study arm from day one of the second study arm. A timeline for the 5-day study arms based on a 10:00-14:00 h day $4 \mathrm{O}_{3}$ exposure is shown in table 3 . A loading dose of $500 \mathrm{mg}$ azithromycin or placebo was given on day $1(73.5 \mathrm{~h}$ prior to day 4 ozone exposure, $95.5 \mathrm{~h}$ prior to day 5 sputum induction) and was followed by a $250 \mathrm{mg}$ dose on day $2(49.5 \mathrm{~h}$ prior to $\mathrm{O}_{3}$ exposure, $71.5 \mathrm{~h}$ prior to sputum induction), a 250 mg dose on day 3 (25.5 h prior to $\mathrm{O}_{3}$ exposure, $47.5 \mathrm{~h}$ prior to sputum induction), and a $250 \mathrm{mg}$ dose on day 4 $\left(1.5 \mathrm{~h}\right.$ prior to $\mathrm{O}_{3}$ exposure, $23.5 \mathrm{~h}$ prior to sputum induction). The total dose administered was thus $1,250 \mathrm{mg}$. The investigators directly observed the taking of 81 of the 120 pills ( $250 \mathrm{mg}$ each) administered to subjects. The 4-h exposures to 0.2 parts per million (ppm) $\mathrm{O}_{3}$ consisted of 30 min periods of exercise alternating with 30 -min periods of rest. After completing the 4-h exposure, subjects performed spirometry manoeuvres every 15 min until the FEV 1 returned to within $5 \%$ of the pre-exposure level. Subjects filled out symptom questionnaires immediately pre- and post- exposure ranking on a scale of $0-4$ (with 4 being the most severe) the following symptoms: anxiety, chest discomfort or chest tightness, chest pain on deep inspiration, cough, eye irritation, headache, nasal irritation, nausea, phlegm or sputum production, shortness of breath, throat irritation, and wheezing. 
Table 3. - Timeline for a 5-day study arm

\begin{tabular}{|c|c|c|}
\hline Day & Time & Treatment protocol \\
\hline \multirow[t]{2}{*}{1} & 08:00 & Sputum induction \\
\hline & $08: 30$ & $\begin{array}{l}\text { Admin. of azithromycin }(500 \mathrm{mg}) \\
\text { or placebo }\end{array}$ \\
\hline 2 & 08:30 & $\begin{array}{l}\text { Admin. of azithromycin }(250 \mathrm{mg}) \\
\text { or placebo }\end{array}$ \\
\hline \multirow[t]{2}{*}{3} & 08:30 & $\begin{array}{l}\text { Admin. of azithromycin }(250 \mathrm{mg}) \\
\text { or placebo }\end{array}$ \\
\hline & Afternoon & Methacholine challenge \\
\hline \multirow[t]{2}{*}{4} & $08: 30$ & $\begin{array}{l}\text { Admin. of azithromycin }(250 \mathrm{mg}) \\
\text { or placebo }\end{array}$ \\
\hline & $10: 00$ & $\begin{array}{l}\text { Ozone exposure followed by } \\
\text { methacholine challenge } 2 \mathrm{~h} \text { after } \\
\text { FEV1 returns to within } 5 \% \text { of baseline }\end{array}$ \\
\hline 5 & 08:00 & Sputum induction \\
\hline
\end{tabular}

Admin.: administration; FEV1: forced expiratory volume in one second.

\section{Statistical analyses}

For comparisons within both conditions, the pre- and post-exposure values were used. For comparing the azithromycin to the placebo condition, the post- minus pre-exposure value ( $\Delta$ value) for both conditions was used. Most of the cell count, biochemical, and spirometric lung function data were not normally distributed. Therefore, all comparisons were performed using the Wilcoxon signed rank test. The alpha level for statistical significance was set at $\mathrm{p}<0.05$.

\section{Results}

\section{Total and differential cell counts}

Neutrophils, lymphocytes, eosinophils, and macrophages were measured as a percentage of leukocytes; columnar cells were measured as a percentage of nonsquamous cells. There was a significant pre- to post-exposure increase in both the per cent neutrophils (table $4 ; p<0.005$ ) and the total cell count (table $4 ; \mathrm{p}<0.05)$ in both the azithromycin and placebo conditions, but no significant difference in the $\Delta$ value between conditions was found for either the per cent neutrophils (fig. 1) or total cell count (median/interquartile range for azithromycin versus placebo, 102.3/47.4-323.5 versus 49.8/20.5-273.8). No significant pre- to post-exposure changes in the per cent lymphocytes or in the per cent eosinophils were found in either the azithromycin or the placebo condition (table 4). However, there was a significant pre- to post-exposure decrease in both the per cent macrophages and the per cent columnar cells in both azithromycin (table $4 ; \mathrm{p}<$ 0.005 and $\mathrm{p}=0.001$, respectively) and placebo (table 4; $\mathrm{p}<0.01$ and $\mathrm{p}<0.005$, respectively) conditions. No difference in the $\Delta$ value between conditions was found for per cent macrophages, per cent eosinophils, per cent lymphocytes, or per cent columnar cells (fig. 1).

\section{Biochemical assays}

There was a pre- to post-exposure increase in concentrations of IL- 6 and IL-8 (table 5; $<<0.001$ and $p<0.005$, respectively) in the azithromycin condition and $p<0.005$ for both in the placebo condition, but no significant difference in the $\Delta$ value between conditions was found for either cytokine (fig. 2). A significant pre- to post-exposure increase in MPO was seen in the azithromycin condition (table $5 ; \mathrm{p}<0.001$ ), but the increase did not reach statistical significance in the placebo group (table $5 ; \mathrm{p}=$ 0.09 ). No significant difference in the $\Delta$ value between conditions was found for MPO (fig. 2). Finally, the authors observed no significant pre- to post-exposure change in total protein levels in either the azithromycin or the placebo condition (table 5) and again no significant difference in the $\Delta$ value between conditions was found (fig. 2).

\section{Spirometric lung function and symptoms}

Significant pre- to post-exposure decreases in FVC and FEV1 (table 6; $<<0.005$ and $\mathrm{p}<0.01$, respectively) were found in both the azithromycin and placebo conditions. In the azithromycin condition compared to the placebo condition, there was no significant difference in the $\Delta$ value between conditions (fig. $3 ; p=0.08$ and $p=0.10$, respectively). A significant pre- to post-exposure increase in the methacholine dose-response was observed for the azithromycin condition (table $6 ; \mathrm{p}<0.005$ ), but the increase in dose-response was not significant for the placebo condition (table $6 ; \mathrm{p}=0.08$ ). No significant difference in the $\Delta$ value between conditions was found for dose response (fig. 3). The authors observed a significant pre- to post-exposure increase in both total and respiratory symptoms in both azithromycin and placebo conditions (table 6; all p<0.005). A significantly smaller $\Delta$ value was found for respiratory symptoms (fig. $3 ; \mathrm{p}<0.05$ ) and no significant difference in the $\Delta$ value for total symptoms (fig. $3 ; \mathrm{p}=0.08$ ) in the azithromycin condition compared to the placebo condition.

Table 4. - Sputum cell counts pre- and post-exposure to ozone $\left(\mathrm{O}_{3}\right)$ in azithromycin and placebo conditions

\begin{tabular}{lccccc}
\hline & \multicolumn{2}{c}{ Azithromycin } & & \multicolumn{2}{c}{ Placebo } \\
\cline { 2 - 3 } \cline { 5 - 6 } & \multicolumn{1}{c}{ Pre-O } & Post-O & & Pre-O $_{3}$ & Post-O $_{3}$ \\
\hline Total cells $\times 10^{4} \cdot \mathrm{mL}^{-1}$ & $135.5(120.5-232.9)$ & $336.3^{*}(200.0-539.0)$ & & $142.3(113.5-206.0)$ & $245.0^{*}(142.5-451.0)$ \\
Neutrophils & $51.2(44.1-61.8)$ & $73.2^{*}(61.4-79.6)$ & & $54.2(42.5-64.2)$ & $71.7^{*}(64.0-77.4)$ \\
Macrophages & $39.9(34.5-47.1)$ & $19.1 *(17.1-24.7)$ & & $43.2(27.0-52.9)$ & $22.7^{*}(15.2-31.6)$ \\
Lymphocytes & $4.0(1.3-5.0)$ & $2.8(1.2-6.4)$ & & $2.9(1.6-3.7)$ & $2.5(1.0-5.4)$ \\
Eosinophils & $0.8(0.3-2.1)$ & $0.7(0.3-2.1)$ & & $1.1(0.4-2.6)$ & $1.5(0.5-4.2)$ \\
Columnar cells & $8.9(4.6-16.3)$ & $2.2^{*}(0.3-6.0)$ & & $11.8(5.7-15.1)$ & $1.6^{*}\left(0.6-3.6^{*}\right)$ \\
\hline
\end{tabular}

Values are median (interquartile range). Median values are given as a percentage unless indicated otherwise. Columnar cells, per cent of nonsquamous cells; all others, per cent of leukocytes. *: Post- $\mathrm{O}_{3}$ value is significantly different from Pre- $_{3}$ value for a given condition $(\mathrm{p}<0.05)$ 


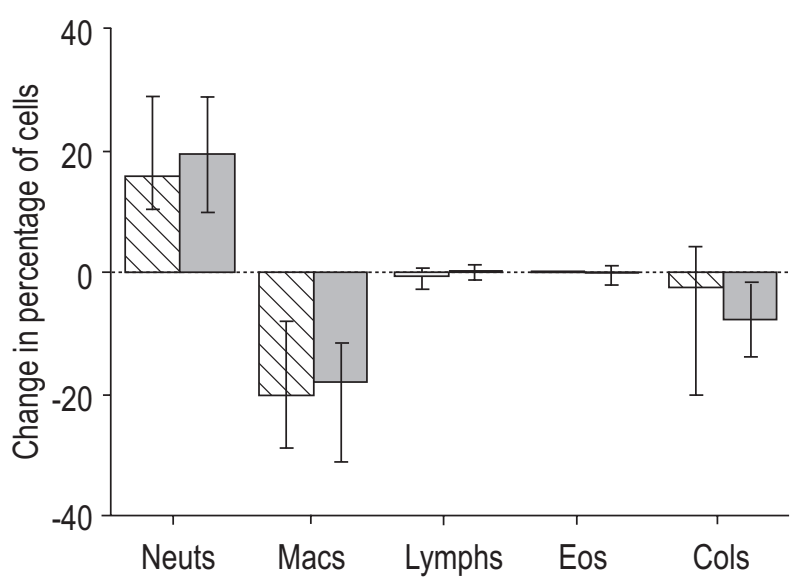

Fig. 1. - Differential cell counts in sputum (post-minus pre-exposure $\Delta$ ) in azithromycin and placebo conditions. Data are medians with interquartile range. Change in all cell types except columnar cells is expressed as a percentage of leukocytes; change in columnar cells is expressed as a percentage of nonsquamous cells. Neuts: neutrophils; Macs: macrophages; Lymphs: lymphocytes; Eos: eosinophils; Cols: columnar cells. $\mathbb{Q}$ : azithromycin; $\square$ placebo.

\section{Discussion}

The results of this experiment do not support the hypothesis that pre-treatment with azithromycin would lessen the $\mathrm{O}_{3}$-induced increases in IL-8 concentration and per cent neutrophils in induced sputum. In both azithromycin and placebo conditions, there were significant pre- to postexposure increases in IL-6, IL-8, total cells, and per cent neutrophils. The authors were unable, however, to find a significant difference in the $\Delta$ value between conditions for any of these variables. In fact, none of the inflammatory variables under study was shown to be significantly affected by administration of azithromycin compared to placebo. Somewhat surprisingly, the authors did demonstrate for the azithromycin condition a significant reduction in the $\Delta$ value for respiratory symptoms relative to placebo. The authors also observed for the azithromycin condition compared to placebo a nonsignificant reduction in the $\Delta$ value for total symptoms and a nonsignificant difference in the delta values pointing toward smaller FEV1 and FVC decrements.

The results seem to disagree with recent experiments that suggest that macrolide antibiotics exert an inhibitory effect on IL-8 production and neutrophil chemotaxis. With the exception of TAMAOKI et al. [11], who studied guinea pig tracheas, all previous studies in this area have been in vitro experiments. It is therefore possible that the results

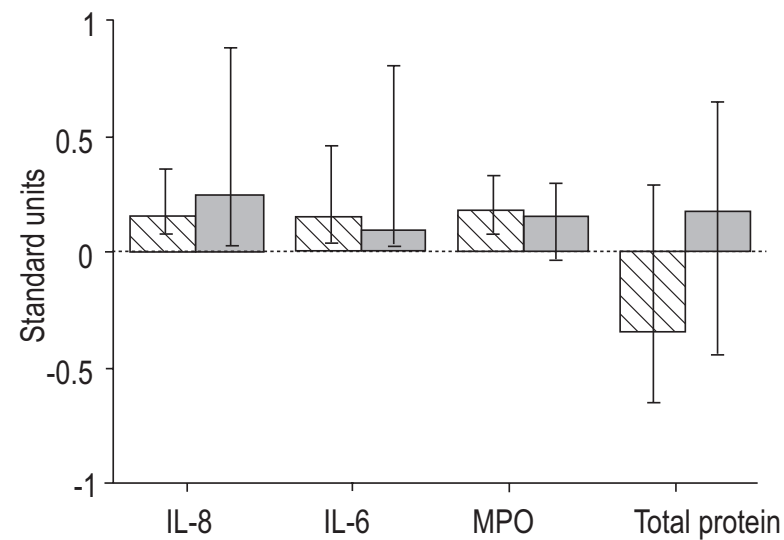

Fig. 2. - Concentrations of inflammatory mediators in sputum (postminus pre-exposure $\Delta$ ) in azithromycin and placebo conditions. Data are medians with interquartile range. Standard units for interleukin (IL)$8=\times 10^{-8} \mathrm{~g} \cdot \mathrm{mL}^{-1}$, for IL- $6=\times 10^{-9} \mathrm{~g} \cdot \mathrm{mL}^{-1}$, for myeloperoxidase (MPO) $=\times 10^{-7} \mathrm{~g} \cdot \mathrm{mL}^{-1}$ and for total protein $=\mathrm{mg} \cdot \mathrm{mL}^{-1}$. $\mathbb{\mathbb { N }}$ : azithromycin; placebo.

obtained differ from those of previous studies due to the fact that the current study was an in vivo experiment with human subjects.

Use of induced sputum to measure biochemical markers of inflammation is a relatively new technique. Confirming the work of FAHY et al. [6] and Hiltermann et al. [7], the current authors demonstrated in both conditions a pre- to post-exposure increase in per cent neutrophils in induced sputum. The decrease in the differential per cent of columnar cells as a function of $\mathrm{O}_{3}$ exposure in both the placebo and azithromycin conditions in this experiment, is contrary to the increase in epithelial cells sampled in proximal airway lavage [3]. This difference could be due to the different regions of the airways sampled by the two techniques, and/or the form of cell removal used in the techniques (coughing versus lavage). Like FAHY et al. [6], the current authors also found a significant pre- to postexposure increase in MPO, although only for the azithromycin condition. To the authors' knowledge, they are the first group to show significant pre- to post- $\mathrm{O}_{3}$-exposure increases in IL-8 and IL-6 in induced sputum.

The data suggest that macrolide antibiotics may not significantly reduce IL-8 production and neutrophil chemotaxis in humans, although other factors could also account for the negative results. While strong evidence exists that 14-member ring macrolides such as erythromycin, clarithromycin and roxithromycin inhibit in vitro IL-8 production and neutrophil chemotaxis, evidence is limited that

Table 5. - Concentrations of inflammatory mediators in sputum pre- and post-exposure to ozone $\left(\mathrm{O}_{3}\right)$ in azithromycin and placebo conditions

\begin{tabular}{|c|c|c|c|c|c|}
\hline & \multicolumn{2}{|c|}{ Azithromycin } & \multicolumn{3}{|c|}{ Placebo } \\
\hline & Pre- $\mathrm{O}_{3}$ & Post- $\mathrm{O}_{3}$ & Pre- $\mathrm{O}_{3}$ & & Post- $\mathrm{O}_{3}$ \\
\hline IL-8 pg.mL ${ }^{-1}$ & $3745.0(1811.2-5313.6)$ & $5240.0 *(2588.2-13854.0)$ & $2323.6(1645.4-4210.4)$ & $5019.6^{*}$ & $=(2721.0-14421.0)$ \\
\hline IL-6 pg.mL $\mathrm{mL}^{-1}$ & $52.4(28.4-180.1)$ & $281.8 *(79.7-514.9)$ & $43.6(26.6-76.0)$ & $167.4 *$ & $=(47.9-1030.8)$ \\
\hline $\mathrm{MPO} \mathrm{ng} \cdot \mathrm{mL}^{-1}$ & $26.9(19.7-37.2)$ & $47.4 *(33.6-65.7)$ & $26.3(15.5-44.9)$ & 37.0 & $(31.9-56.1)$ \\
\hline Total protein $\mu \mathrm{g} \cdot \mathrm{mL}^{-1}$ & $2865.6(2734.7-3660.9)$ & $2858.1 \quad(2248.0-3258.5)$ & $2704.7(2139.7-3019.1)$ & 2985.0 & $(2195.4-3283.8)$ \\
\hline
\end{tabular}

Values are median (interquartile range). IL: interleukin. MPO: myeloperoxidase. *: Post- $\mathrm{O}_{3}$ value is significantly different from Pre- $\mathrm{O}_{3}$ value for a given condition $(\mathrm{p}<0.05)$. 


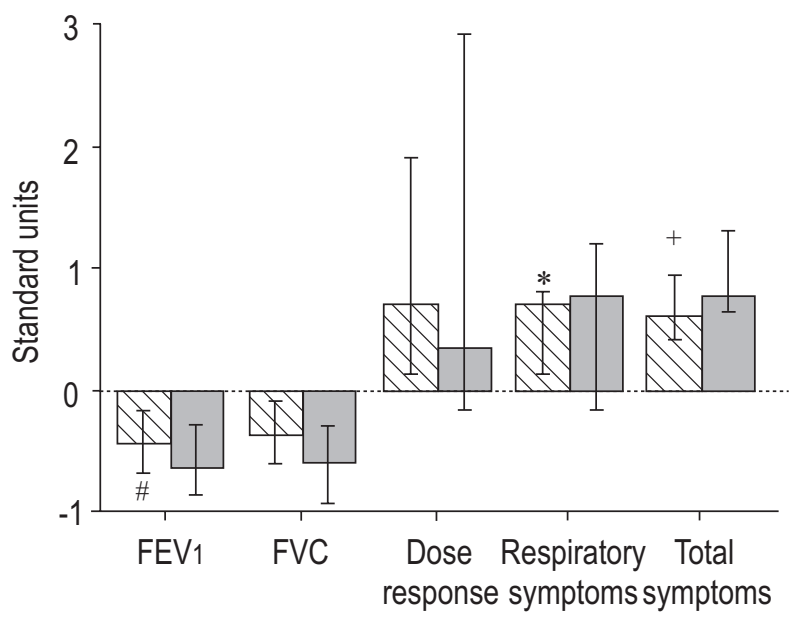

Fig. 3. - Lung function and symptom parameters (post-minus preexposure $\Delta$ ) in azithromycin and placebo conditions. Data shown are medians with interquartile range. Standard units for forced expiratory volume in one second (FEV1) and forced vital capacity (FVC)=litres, for dose response $=$ percentage drop in $\mathrm{FEV} 1 \cdot \mu \mathrm{mol}^{-1}$ methacholine, and for respiratory symptoms and total symptoms $=10^{-1}$ units. *: Azithromycin value significantly different to placebo value $(\mathrm{p}<0.05) ;{ }^{\#}: \mathrm{p}=0.10 ;{ }^{+}$: $\mathrm{p}=0.08$. $\mathbb{\mathbb { N }}$ : azithromycin; placebo.

azithromycin, a 15-member ring macrolide, exerts a similar anti-inflammatory action. Only one study has shown azithromycin to inhibit neutrophil chemotaxis and active oxygen generation [17]. Also, azithromycin has been shown not to change TNF- $\alpha$, IL-1 $\beta$, or IL-6 levels in alveolar macrophages or blood [15]. The possibility that azithromycin, by virtue of its 15-member ring, lacks the requisite structure conferring anti-inflammatory activity to the 14member ring macrolides is made more likely by the observation that 16-membered macrolides such as josamycin do not reduce IL-8 production [10]. Secondly, there are considerable difficulties encountered in determining the optimal dose of azithromycin to administer to human subjects to test for anti-inflammatory activity. One such difficulty is the relatively sparse and often conflicting pharmacokinetic data. In two studies a single $500 \mathrm{mg}$ dose of azithromycin was administered to human subjects; in one study [16] peak azithromycin concentration in alveolar cells occurred at $120 \mathrm{~h}$ post dosing while in the other study [13] peak azithromycin concentrations in bronchial mucosa, epithelial lining fluid, and alveolar macrophages occurred $48 \mathrm{~h}$ post dosing. Other problems include uncertainty about the exact site of the proposed anti-inflammatory action of macrolide antibiotics and the need to generalize from studies of different macrolides. Thus, further work needs to be carried out in order to determine optimal dosing schedules. These difficulties notwithstanding, several human cell line studies found that at concentrations of $5-10 \mu \mathrm{g} \cdot \mathrm{mL}^{-1}$, various 14-member macrolides inhibit IL-8 production [8-10]. Given a bronchial mucosal value of $3.9 \mu \mathrm{g} \cdot \mathrm{mL}^{-1}$ measured $48 \mathrm{~h}$ after a single $500 \mathrm{mg}$ dose of azithromycin [13], and an alveolar macrophage concentration of $51.6 \mu \mathrm{g} \cdot \mathrm{mL}^{-1}$ measured $24 \mathrm{~h}$ after a 3 -day course of $500 \mathrm{mg}$ per day [15], and given that tissue levels of azithromycin should continue to accumulate with serial doses, the current protocol may indeed have led to bronchial mucosal concentrations in the range of $5-10 \mu \mathrm{g} \cdot \mathrm{mL}^{-1}$.

While the current results must be interpreted with caution, the failure of azithromycin to significantly lessen, relative to placebo, the pre- to post-exposure increases in IL-8 concentration and in per cent neutrophils argues that in human airways the antibiotic lacks anti-inflammatory action on these variables at the dose under study. Further in vitro work to more completely characterize the proposed anti-inflammatory action of azithromycin, in particular its effect on IL-8 production, is needed to more completely understand the results of the experiment. Further characterization of the exact site of the proposed anti-inflammatory action of macrolide antibiotics is also needed in order to better use existing pharmacokinetic data to determine an appropriate oral dose to administer to human subjects. The finding that azithromycin causes a significant reduction in respiratory symptoms and a nonsignificant reduction in the magnitude of the FVC and FEV1 decrements following exposure to $\mathrm{O}_{3}$ argues for investigation into whether these changes are due to known antimicrobial or unknown analgesic effects of the drug. One recent study [21] found that asthmatics treated with clarithromycin for 6 weeks showed decreased expression of neurokinin-1 (NK-1) and substance $\mathrm{P}(\mathrm{SP})$ relative to asthmatics treated with placebo. This reduction in neurogenic inflammation, which the authors believe results from treatment of mycoplasma infections, may also be due to direct effects of clarithromycin. Thus, azithromycin may reduce respiratory symptoms by reducing $\mathrm{O}_{3}$-induced neurogenic inflammation.

It is possible that independent variables not utilized in this experiment, including the subject group (airway pathophysiology), azithromycin dose, and sampling time, could produce different results to those of this experiment. It is also possible that an anti-inflammatory effect on dependent

Table 6. - Lung function, airway responsiveness, and symptom parameters pre- and post-exposure to ozone $\left(\mathrm{O}_{3}\right)$ in azithromycin and placebo conditions

\begin{tabular}{|c|c|c|c|c|}
\hline & \multicolumn{2}{|c|}{ Azithromycin } & \multicolumn{2}{|c|}{ Placebo } \\
\hline & Pre- $\mathrm{O}_{3}$ & Post- $\mathrm{O}_{3}$ & Pre- $\mathrm{O}_{3}$ & Post- $\mathrm{O}_{3}$ \\
\hline FEV1 L & $4.17(3.46-4.87)$ & $3.94 *(3.08-4.47)$ & $4.20(3.42-5.04)$ & $3.51 *(2.60-4.08)$ \\
\hline FVC L & $4.96(4.25-5.85)$ & $4.75 *(3.74-5.59)$ & $5.04(4.25-6.04)$ & $4.38 *(3.07-5.30)$ \\
\hline Dose response & $0.24(-0.06-0.79)$ & $0.84 *(0.29-2.36)$ & $0.52(0.22-2.03)$ & $0.98 \quad(0.37-4.03)$ \\
\hline Resp. symptoms & $0.0 \quad(0.0-1.8)$ & $7.0 * \quad(3.0-7.8)$ & $0.0 \quad(0.0-2.0)$ & $9.0 * \quad(4.3-12.3)$ \\
\hline Total symptoms & $1.0 \quad(0.0-4.0)$ & $9.0^{*}(8.0-11.0)$ & $2.0 \quad(0.0-5.0)$ & $12.0 * \quad(6.0-15.0)$ \\
\hline
\end{tabular}

Values are median (interquartile range). FVC: forced vital capacity. Resp.: respiratory; dose-response: methacholine dose-response (percentage drop in forced expiratory volume in one second $(\mathrm{FEV} 1) \cdot \mu \mathrm{mol}^{-1}$ methacholine). *: Post- $\mathrm{O}_{3}$ value is significantly different from Pre- $\mathrm{O}_{3}$ value for a given condition $(\mathrm{p}<0.05)$. 
variables not measured in this experiment, including cellular viability and function, and regional differences in the airway, could have occurred in this experiment. While there are some limitations to the current study, the authors have clearly demonstrated a strong ozone effect on per cent neutrophils and interleukin- 8 concentrations, but failed to find any evidence for anti-inflammatory activity of azithromycin on the biochemical and cellular variables under study. This suggests that, in healthy subjects, in the design used in this experiment, azithromycin, in usual clinical doses, does not have anti-inflammatory effects on human airways as indicated in the measured variables.

\section{References}

1. Seltzer J, Bigby BG, Stulbarg M, Holtzman MJ, Nadel JA. $\mathrm{O}_{3}$-induced change in bronchial reactivity to methacholine and airway inflammation in humans. J Appl Physiol 1986; 60: 1321-1325.

2. Koren H, Devlin RB, Graham D, et al. Ozone-induced inflammation in the lower airways of human subjects. $A m$ Rev Respir Dis 1989; 139: 407-415.

3. Aris RM, Christian D, Hearne PQ, Kerr K, Finkbeiner WE, Balmes JR. Ozone-induced airway inflammation in human subjects as determined by airway lavage and biopsy. Am Rev Respir Dis 1993; 148: 1363-1372.

4. Balmes JR, Chen LL, Scannell C, et al. Ozone-induced decrements in FEV1 and FVC do not correlate with measures of inflammation. Am J Respir Crit Care Med 1996; 153: 904-909.

5. Bascom R, Bromberg PA, Costa DA, et al. Health effects of outdoor air pollution. Am J Respir Crit Care Med 1996; 153: 3-50.

6. Fahy JV, Wong HH, Liu JT, Boushey HA. Analysis of induced sputum after air and ozone exposures in healthy subjects. Environ Res 1995; 70: 77-83.

7. Hiltermann TJ, Stolk NJ, Hiemstra PS, et al. Effect of ozone exposure on maximal airway narrowing in nonasthmatic and asthmatic subjects. Clin Sci 1995; 89: 619624.

8. Khair OA, Devalia JL, Abdelaziz MM, Sapsford RJ, Davies RJ. Effect of erythromycin on Haemophilus influenzae endotoxin-induced release of IL-6, IL-8 and sICAM-1 by cultured human bronchial epithelial cells. Eur Respir J 1995; 8: 1451-1457.

9. Fujii T, Kadota JI, Morikawa T, et al. Inhibitory effect of erythromycin on interleukin 8 production by $1 \alpha, 25$ dihydroxyvitamin D3-stimulated THP-1 cells. Antimicrob Agents Chemother 1996; 40(6): 1548-1551.

10. Takizawa H, Desaki M, Ohtoshi T, et al. Erythromycin modulates IL-8 expression in normal and inflamed human bronchial epithelial cells. Am J Respir Crit Care Med 1997; 156: 266-271.

11. Tamaoki J, Nakata J, Tagaya E, Konno K. Effects of roxithromycin and erythromycin on interleukin 8-induced neutrophil recruitment and goblet cell secretion in guinea pig tracheas. Antimicrob Agents Chemother 1996; 40: 1726-1728.

12. Hotta M. Neutrophil chemotactic activity in cryptogenic organizing pneumonia and the response to erythromycin. Kurume Med J 1996; 43: 207-217.

13. Baldwin DR, Wise R, Andrews JM, Ashby JP, Honeybourne D. Azithromycin concentrations at the sites of pulmonary infection. Eur Respir J 1990; 3: 886-890.

14. Kraft M, Cassell GH, Bettinger CM, Duffy LB, Pak J, Martin RJ. Mycoplasma pneumoniae as a cofactor in chronic asthma. Am JRespir Crit Care Med 1997; 155: A65.

15. Aubert J-D, Juillerat-Jeanneret L, Fioroni P, Dayer P, Plan P-A, Leuenberger P. Function of human alveolar macrophages after a 3-day course of azithromycin in healthy volunteers. Pul Pharmacol Ther 1998; 11: 263-269.

16. Conte JE Jr, Golden J, Duncan S, McKenna E, Lin E, Zurlinden E. Single-dose intrapulmonary pharmacokinetics of azithromycin, clarithromycin, ciprofloxacin, and cefuroxime in volunteer subjects. Antimicrob Agents Chemother 1996; 40: 1617-1622.

17. Sugihara E. Effect of macrolide antibiotics on neutrophil function in human peripheral blood. Kansenshogaku Zasshi J Jpn Assoc Infec Dis 1997; 71: 329-336.

18. American Thoracic Society. Standardization of spirometry 1994 update. Am J Respir Crit Care Med 1995; 152: $1107-1136$.

19. Kanner RE, Connet JE, Altose MD, et al. Gender difference in airway hyperresponsiveness in smokers with mild COPD; The Lung Health Study. Am J Respir Crit Care Med 1994; 150: 956-961.

20. O'Connor G, Sparrow D, Taylor D, Segal M, Weiss S. Analysis of dose-response curves to methacholine. Am Rev Respir Dis 1987; 136: 1412-1417.

21. Chu HW, Kraft M, Krause JE, Cortright DN, Martin RJ. Neurokinin-1 (NK-1) and substance P (SP) expression in asthmatic airways - downregulation with clarithromycin. Am J Respir Crit Care Med 1998; 157(3): A24. 